\title{
A retrospective study to assess prevalence of gestational diabetes mellitus among those who delivered in Saveetha Medical College and Hospital
}

\author{
Sharmila Kumar Gopalan', Kohila Kalimuthu ${ }^{2 *}$
}

\author{
${ }^{1}$ MBBS student, Saveetha Medical College and Hospital, Chennai, Tamil Nadu, India \\ ${ }^{2}$ Department of Obstetrics and Gynecology, Saveetha Medical College and Hospital, Chennai, Tamil Nadu, India
}

Received: 23 July 2019

Accepted: 01 August 2019

\author{
*Correspondence: \\ Dr. Kohila Kalimuthu, \\ E-mail: kohilakalimuthu@gmail.com
}

Copyright: (c) the author(s), publisher and licensee Medip Academy. This is an open-access article distributed under the terms of the Creative Commons Attribution Non-Commercial License, which permits unrestricted non-commercial use, distribution, and reproduction in any medium, provided the original work is properly cited.

\begin{abstract}
Background: Gestational diabetes mellitus (GDM) defined as any degree of carbohydrate intolerance with onset or first recognition during pregnancy contributes to about $90 \%$ of diabetes complicating pregnancy. GDM imposes risks for both mother and fetus, some of which continues throughout the life of mother and child. The objective of the present study was to determine the prevalence of gestational diabetes mellitus and the associated risk factors among those who delivered in Saveetha medical college and hospital.

Methods: A retrospective study was conducted by analysing the medical records of the patients who were admitted in the Department of Obstetrics and Gynaecology over a period of 1 year at Saveetha medical college and hospital, Chennai, Tamil Nadu, India. The diagnosis of GDM was made mainly by $75 \mathrm{gm}$ one step oral glucose tolerance test (OGTT). The guideline endorses 2-hours 75-gm OGTT, irrespective of last meal timings with a cut off value of $\geq 140$ $\mathrm{mg} / \mathrm{dl}$. All data was analysed by simple descriptive statistics and percentage method.

Results: In the present study, the total number of deliveries for 1 year from April 2018 - March 2019 were 511 and among those the total number of antenatal mothers with GDM who delivered were 46 . Therefore the prevalence of GDM was calculated to be $9 \%$ or 90 per thousand deliveries. In the present study, $37(65.1 \%)$ pregnant women of GDM group were seen in the age group of above 25 years, 27 (58.59\%) were multiparous, 25(54.25\%) pregnant females with GDM were found to have overweight and obese out of 46 cases.

Conclusions: Our current study concludes the Prevalence of GDM in Saveetha Medical College Hospital is 9\% between April 2018-March 2019. We have identified the following risk factors for developing GDM: multiparity $\geq 2$; previous history of diabetes mellitus; age $\geq 25$; BMI $\geq 25$; and family history of diabetes.
\end{abstract}

Keywords: Gestational diabetes mellitus, Oral glucose tolerance test, Outpatient department

\section{INTRODUCTION}

Gestational diabetes mellitus (GDM) defined as any degree of carbohydrate intolerance with onset or first recognition during pregnancy contributes to about $90 \%$ of diabetes complicating pregnancy. ${ }^{1,2}$ GDM imposes risks for both mother and fetus, some of which continues throughout the life of mother and child. Immediate maternal complications include preeclampsia, need for caesarean sections, and poly/oligohydramnios. ${ }^{3}$ Complications in the baby include hyperinsulinemia, macrosomia, shoulder dystocia, neonatal hypoglycemia, 
and respiratory distress syndrome. Women with GDM are at an increased risk of GDM in future pregnancies and also at a higher risk of developing type 2 diabetes in the future. ${ }^{4}$ GDM also increases the risk of obesity and glucose intolerance in the offspring. ${ }^{5}$ GDM is therefore an important public health issue that has major repercussions for both mother and offspring. Detection of GDM thus provides a window of opportunity to intervene and reduce adverse perinatal outcomes. ${ }^{6}$

Oral glucose tolerance test (OGTT) - It is a screening cum diagnostic test for gestational diabetes mellitus. A red sticker is pasted onto antenatal card for all identified GDM-positive women based on OGTT results. Newly identified GDM-positive women are registered for subsequent management and follow-up. If woman tested positive (2-hour 75 -g OGTT $\geq 140 \mathrm{mg} / \mathrm{dL}$ ), she is managed as per GDM protocols. However, if tested negative, OGTT is repeated at 24-28 weeks ensuring a minimum gap of at least 4 weeks from the first test. It is prudent to ensure second test as many pregnant women develop glucose intolerance during this period. If woman presents beyond 28 weeks, only one test is performed at first point of contact irrespective of gestation. GDM for those who drop out, field health workers make special house visits to perform OGTT among such women.

The objective of this study was to determine the prevalence of gestational diabetes mellitus among those who delivered in Saveetha Medical College and Hospital. To find out the demographic correlation and the associated risk factors

\section{METHODS}

A retrospective study was conducted by analysing the medical records of the patients who were admitted in the department of Obstetrics and Gynaecology over a period of 1 year from April 2018 to March 2019 at Saveetha medical college and hospital, Chennai. It is a tertiary care centre getting referrals from nearby villages and towns. The number of antenatal mothers with gestational diabetes mellitus within the study period were calculated and their demographic details were assessed. A total of 46 cases reported during this frame with gestational diabetes mellitus were admitted at our hospital through emergency or outpatient department. The diagnosis of gestational diabetes mellitus was made mainly by $75 \mathrm{gm}$ one step oral glucose tolerance test (OGTT). GDM is operationally defined as impaired glucose tolerance with onset or first recognition during pregnancy. Its diagnosis is based on single step test. In accordance to World Health Organization recommendations, the guideline endorses 2 hour 75g OGTT, irrespective of last meal timing with a cutoff value of $\geq 140 \mathrm{mg} / \mathrm{dL}$ using a plasmastandardized glucometer. The labour room registers were used to determine the total number of deliveries during this period. The information of each patient was obtained from their case records kept in the medical records department. All relevant demographic data was obtained along with the previous obstetric history and treatment undertaken. All data was analysed by simple descriptive statistics and percentage method.

Retrospective study analysis of case records from the medical records department at Saveetha medical college and hospital. Study duration 1 year between April 2018March 2019. Cases in the past one year, April 2018March 2019. Simple descriptive statistics and percentage method.

\section{Inclusion criteria}

- All pregnant mothers diagnosed of GDM and delivered at Saveetha hospital

- $\quad$ Singleton pregnancy.

\section{Exclusion criteria}

- Antenatal mothers with known diagnosis of overt diabetes

- Multiple pregnancies.

\section{RESULTS}

In the present study, which was conducted over a period of 1 year, the number of deliveries was 511 and the total number of antenatal mothers with GDM Who delivered during the last 1 year April 2018 and March 2019 were 46. Therefore the prevalence of GDM was calculated to be $9 \%$ or 90 per thousand deliveries.

Table 1: Characteristics of study population.

\begin{tabular}{|ll|}
\hline Factors & $\mathbf{N = 4 6}$ \\
\hline Mean maternal age & 26.5 \\
\hline Mean BMI (Body mass index) & 26.4 \\
\hline Mean gestational age & 36 weeks \\
\hline Multiparity $(\geq 2)$ & $58.59 \%$ \\
\hline Mode of delivery & \\
\hline Vaginal delivery & $15.19 \%$ \\
\hline Elective caesarean & $36.89 \%$ \\
\hline Emergency caesarean & $47.74 \%$ \\
\hline
\end{tabular}

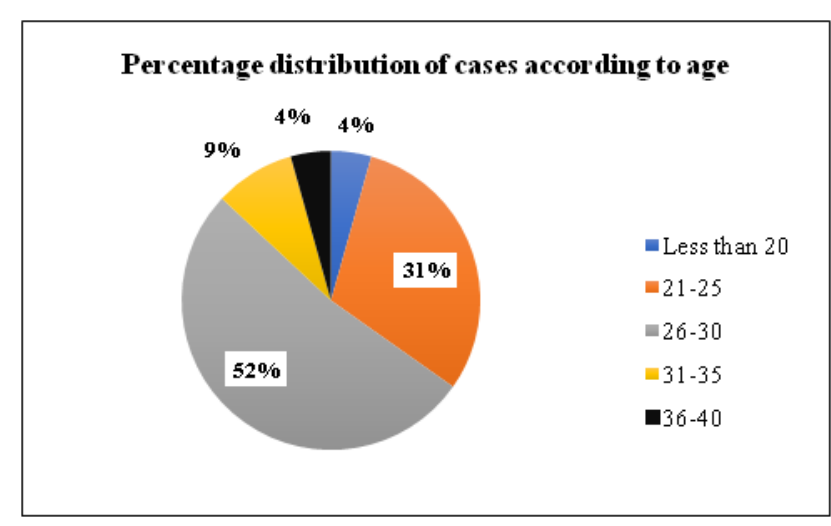

Figure 1: Percentage distribution of cases according to age. 
Among the 46 GDM mothers mean maternal age is 26.5 years, mean BMI is 26.4, mean gestational age at diagnosis is 36 weeks, $58.5 \%$ people are multiparas.

Table 2: Distribution of cases according to age.

\begin{tabular}{|lll|}
\hline Age (years) & $\%$ & $\mathrm{~N}=46$ \\
\hline$<20$ & $4.34 \%$ & 3 \\
\hline $21-25$ & $30.38 \%$ & 16 \\
\hline $26-30$ & $52.08 \%$ & 20 \\
\hline $31-35$ & $8.68 \%$ & 14 \\
\hline $36-40$ & $4.34 \%$ & 3 \\
\hline
\end{tabular}

While assessing the mode of delivery, $84.63 \%$ of GDM mothers were delivered by caesarean section compared to $15 \%$ of normal vaginal delivery.

The overall age group common for gestational diabetes mellitus was found to be between 26-30 years. The mean age of gestational diabetes mellitus was 26.5 years.

Around $4.34 \%$ of GDM cases occurred in extremes of age group that is less than 20 years and more than 36 years.

The overall age group common for gestational diabetes mellitus was found to be between 26-30 years. The mean age of gestational diabetes mellitus was 26.5 years.

Around $4.34 \%$ of GDM cases occurred in age group less than 20 years. $82.46 \%$ of cases were found to be between the age group 21-30 years and $13.02 \%$ above 30 years of age.

Table 3: Distribution of cases according to risk factors.

\begin{tabular}{|l|ll|}
\hline Risk factors & $\%$ & $\mathrm{~N}=46$ \\
\hline Age $>25$ & $65.1 \%$ & 30 \\
\hline Overweight and obesity (BMI $\geq 25)$ & $54.25 \%$ & 25 \\
\hline Multiparity ( $\geq 2)$ & $58.59 \%$ & 27 \\
\hline Family history of diabetes mellitus & $15.19 \%$ & 7 \\
\hline $\begin{array}{l}\text { Previous obstetric history of } \\
\text { diabetes mellitus. }\end{array}$ & $32.55 \%$ & 15 \\
\hline Unexplained recurrent abortions (>2) & $4.34 \%$ & 2 \\
\hline
\end{tabular}

Among the 46 GDM women, 65\% women aged >25 years, $54 \%$ women were overweight, $58.5 \%$ were multiparas.

History of diabetes mellitus present either in family or in Obstetric history for $47.74 \%$ women. And $4.34 \%$ women had unexplained pregnancy losses.

\section{DISCUSSION}

The present study was conducted to evaluate the prevalence of GDM in our society and its association with the different risk factors. The routine antenatal visits and monitoring of serum glucose levels can detect GDM early and thus help in decreasing the maternal complications as well as neonatal morbidity and mortality.

According to our study $46(9 \%)$ were found to have GDM. They were diagnosed of GDM by OGTT measurements in OPD clinics and delivered in Saveetha Hospital. None of these had diabetes previously. This is much similar to some studies done in India. ${ }^{7}$ They also used $75 \mathrm{gm}$ OGTT for screening antenatal mothers coming to OPD. In other study, the prevalence of GDM was found to be $4.2 \%{ }^{1}$ In a study conducted in Services Hospital Lahore the prevalence of GDM was found to be about $1 \% .^{8}$

A general awareness regarding the dietary modifications, effects of healthy diet on physical and mental health are the main factors for the increasing incidence of GDM.

This is more aggravated in the pregnancy by obesity due to imbalanced dietary habits. This is a major risk for developing diabetes..$^{9-11}$ In a study conducted at India by Zargar et al, reported GDM as $3.8 \%$ prevalent. Also the increasing age has been reported to have significant association with prevalence of GDM. ${ }^{12}$

In the present study prevalence of GDM increased significantly with increasing age and $37(65.1 \%)$ pregnant women of GDM group were seen in the age group of above 25 years. A similar association has been seen in earlier studies. ${ }^{13-15}$

Higher numbers of our patients presented with gestational diabetes were multipara $27(58.59 \%)$ in accordance to the findings Seshiah et al, patients and Zargar et al, patients have reported similar findings. ${ }^{15}$ Higher parity has also been present in a study by Kanika et al. ${ }^{15}$

The association between parity and diabetes is strongly linked to obesity and age. Ladies with higher parity often are older and fatter. Obesity is an intermediate outcome in the causal pathway between parity and GDM, probably a mediating factor. Adjustments for BMI, on the other hand could diminish the strength of this. ${ }^{16}$ In our study 25 (54.25\%) pregnant females with GDM were found overweight and obese out of 46 cases. Family history of diabetes is reported to be correlated with increased incidence of GDM. ${ }^{17}$ Similarly in the present study significant association was found between cases with GDM and family history of diabetes mellitus.

GDM increases the risk of fetal macrosomia and a greater potential risk exists for shoulder dystocia in macrosomic infants. ${ }^{18-21}$ In spite of a higher rate of macrosomia in the GDM group, there were no cases of shoulder dystocia. This is possibly because of the high rate of caesarean section in the GDM group (47.64\%). The decision for caesarean section was often made due to the high rate of associated complications (e.g., macrosomia and 
gestational hypertension) and accounts for the lower gestational age at delivery in the GDM group.

Clinical recognition of GDM is important because therapy including medical, nutrition therapy, insulin when necessary, and antepartum fetal surveillance, can reduce the perinatal morbidity and mortality associated with GDM. ${ }^{22}$ In this study, out of the 46 GDM cases, 27 were on insulin therapy and 4 were on Oral hypoglycemic agents and 3 were on meal plan.

\section{CONCLUSION}

Our current study provides an estimation of the prevalence and risk factors of GDM in Saveetha Medical College. Prevalence of GDM in Saveetha medical college is 9\% between April 2018-March 2019. We have identified the following risk factors for developing GDM: multiparity $\geq 2$; previous history of diabetes mellitus; age $\geq 25$; $\mathrm{BMI} \geq 25$; and family history of diabetes.

It is important that the risks factors for GDM are recognized in order the clinicians are able to identify those at risk of getting GDM for early diagnosis and further intervention. We recommend that clinicians screen for GDM as early as possible among those with risk factors using one-step screening method instead of two-step screening method. If the results are negative, the test should be repeated in between 24 and 28 weeks of gestation.

\section{ACKNOWLEDGMENTS}

Author would like to thank Dr. Saveetha Rajesh, Director for providing me an opportunity to do the project work in Saveetha Medical College and Hospital and giving us all support and guidance which made me complete the project duly.

Author thankful to and fortunate enough to get constant encouragement, support and guidance from all teaching staffs of Department of obstetrics and gynaecology which helped us in successfully completing our project work.

Funding: No funding sources

Conflict of interest: None declared

Ethical approval: The study was approved by the Institutional Ethics Committee

\section{REFERENCES}

1. Metzger BE, Coustan DR. Summary and Recommendations of the Fourth International Workshop-Conference on Gestational Diabetes Mellitus. The Organizing Committee. Diabetes Care. 1998;21:B161-7.

2. Expert Committee on the Diagnosis and Classification of Diabetes Mellitus. Report of the expert committee on the diagnosis and classification of diabetes mellitus. Diabetes Care. 2003;26(Suppl 1):S5-20.

3. Wendland EM, Torloni MR, Falavigna M, Trujillo J, Dode MA, Campos MA, et al. Gestational diabetes and pregnancy outcomes - a systematic review of the World Health Organization (WHO) and the International Association of Diabetes in Pregnancy Study Groups (IADPSG) diagnostic criteria. BMC Pregnancy Childbirth. 2012;12:23.

4. Mpondo BC, Ernest A, Dee HE. Gestational diabetes mellitus: challenges in diagnosis and management. J Diabetes Metab Disord. 2015;14:42.

5. Jovanovic L, Pettitt DJ. Gestational diabetes mellitus. JAMA. 2001;286:2516-8.

6. Mithal A, Bansal B, Kalra S. Gestational diabetes in India: Science and society. Indian $\mathrm{J}$ Endocrinol Metab. 2015;19:701-4.

7. Seshiah V, Balaji V, Balagi MS, Sanjeevi CB, Green A. Gestational diabetes mellitus in India. J Assoc Physicians India. 2004;52:707-11.

8. Junaid K, Sohail R, Zaman F. Screening for gestational diabetes. J Surg Pakistan. 2002;7(4):5-7.

9. Hassan A. Screening of pregnant women for gestational diabetes mellitus. J Ayub Med Coll Abottabad. 2005;17(2):54-8.

10. King H, Rewess M. Diabetes in adult is now a third world problem. The WHO Adhoc diabetes reporting group, Bull, WHO. 1991;69:643-8.

11. Lolemans K, Calumaets S, Van Asshe FA. Diet induced obesity in the rats. A model for GDM. Am J Obstet Gynaecol. 2004;190(3):858-65.

12. Kalyani KR, Jajoo S, Hariharan C, Samal S. Prevalence of GDM, its associated risk factors and pregnancy outcomes at a rural setup in Central India. Int $\mathrm{J}$ Reprod Contracept Obstet Gynaecol. 2014;3(1):219-24.

13. Zargar AH, Sheikh MI, Bashir M. Prevalence of GDM in Kashmiri women in Indian subcontinent. Diabetes Res Clin Pract. 2004;66(2):139-45.

14. Seshiah V, Balaji V, Balaji MS, Paneerselvam A, Arthi T, Thamizharsi M, et al. Prevalence of GDM in South India (Tamil Nadu): a community study. J Assoc Physicians India. 2008;56:329-33.

15. Sawami SR, Mehetra R, Shivane V, Bandgar TR, Menon PS, Shah NS. Prevalence of carbohydrate intolerance of varying degrees in pregnant females in western India (Maharashtra): A hospital Based Study. J Indian Med Assoc. 2008;106:712-4.

16. Tolorani MR, Betran AP, Horta BL, Nakamura MU, Atallah AN, Moron AF, et al. Pregnancy BMI and the risk of gestational diabetes: a systematic review of the literature with meta-analysis. Obes Rev. 2009;10:194-203.

17. Kim C, Lin T, Valdez R, Beckles GL. Does frank diabetes first degree relatives of a pregnant woman affect the likelihood of her developing GDM or nongestational diabetes? Am J Obstet Gynecol. 2009;201(576):1-6.

18. Garcia-Patterson A, Corcoy R, Balsells M, Altirriba O, Adelantado JM, Cabero L, et al. In pregnancies 
with gestational diabetes mellitus and intensive therapy, perinatal outcome is worse in small-forgestational age newborns. Am J Obstet Gynecol. 1998;179:481-5.

19. Turok DK, Ratcliff SD, Baxley EG. Management of gestational diabetes mellitus. Am Fam Physician. 2003;68:1767.

20. Littleton LY, Engebretson JC. Maternal Neonatal and Women's Health Nursing, Delmar, Thomson Learning Inc., Australia. 2002:825.

21. Watkins PJ. Pregnancy in diabetes, success or failure? Diabet Med. 1998;15:95.
22. American Diabetes Association, Report of the Expert Committee on the Diagnosis and Classification of Diabetes Mellitus, Diabet Care. 2003;26:5-20.

Cite this article as: Goplalan SK, Kalimuthu K. A retrospective study to assess prevalence of gestational diabetes mellitus among those who delivered in saveetha medical college and hospital. Int J Reprod Contracept Obstet Gynecol 2019;8:3475-9. 